\title{
Operational flood management under large-scale extreme conditions, using the example of the Middle Elbe
}

\author{
A. Kron ${ }^{1}$, F. Nestmann ${ }^{1}$, I. Schlüter ${ }^{2}$, G. Schädler ${ }^{2}$, C. Kottmeier ${ }^{2}$, M. Helms ${ }^{1}$, R. Mikovec ${ }^{1}$, J. Ihringer ${ }^{1}$, M. Musall ${ }^{1}$, \\ P. Oberle ${ }^{1}$, U. Saucke ${ }^{6, *}$, A. Bieberstein ${ }^{3}$, J. Daňhelka ${ }^{4}$, and J. Krejčí ${ }^{5}$ \\ ${ }^{1}$ Institute for Water and Water Resources Management, KIT, Karlsruhe, Germany \\ ${ }^{2}$ Institute for Meteorology and Climate Research, KIT, Karlsruhe, Germany \\ ${ }^{3}$ Institute of Soil Mechanics and Rock Mechanics, KIT, Karlsruhe, Germany \\ ${ }^{4}$ Czech Hydrometeorological Institute, Prague, Czech Republic \\ ${ }^{5}$ AquaLogic Consulting Ltd., Prague, Czech Republic \\ ${ }^{6}$ Dr.-Ing. Ulrich Saucke, Consulting Engineer for Geotechnics, Kronberg, Germany \\ *formerly at: Institute of Soil Mechanics and Rock Mechanics, KIT, Karlsruhe, Germany
}

Received: 22 December 2009 - Revised: 27 April 2010 - Accepted: 28 April 2010 - Published: 10 June 2010

\begin{abstract}
In addition to precautionary or technical flood protection measures, short-term strategies of the operational management, i.e. the initiation and co-ordination of preventive measures during and/or before a flood event are crucially for the reduction of the flood damages. This applies especially for extreme flood events. These events are rare, but may cause a protection measure to be overtopped or even to fail and be destroyed. In such extreme cases, reliable decisions must be made and emergency measures need to be carried out to prevent even larger damages from occurring.

Based on improved methods for meteorological and hydrological modelling a range of (physically based) extreme flood scenarios can be derived from historical events by modification of air temperature and humidity, shifting of weather fields and recombination of flood relevant event characteristics. By coupling the large scale models with hydraulic and geotechnical models, the whole flood-process-chain can be analysed right down to the local scale. With the developed GIS-based tools for hydraulic modelling Flow GIS and the Dike-Information-System, (IS-dikes) it is possible to quantify the endangering shortly before or even during a flood event, so the decision makers can evaluate possible options for action in operational mode.
\end{abstract}

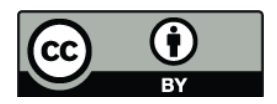

Correspondence to: A. Kron (kron@kit.edu)

\section{Introduction}

Sustainable flood management includes technical flood protection measures as well as consistent realisation of precautionary measures in endangered areas like for example adapted land use and methods of construction. Strategies of operational flood management, like short-time initiation and coordination of protective measures during or shortly before a flood event, have also crucial impact on reduction of the extent of damages. This applies particularly to extreme events, exceeding the design case of precautionary measures. Recent extreme flood events, like those of August 2002 and MarchApril 2006 at the Elbe river, revealed that a concept of an integrated quantification is especially in large river basins the only chance of an effective risk management and joint accomplishment of a catastrophic event. Therefore, tools enabling decision makers to rapidly identify current large-scale as well as local endangering and evaluate possible options for action with regard to their effectiveness are necessary. In this context, the overall objectives in the presented research project were:

1. Improvement of existing methods for an integrated quantification of realistic (physically based) extreme flood events within the flood-process-chain: Meteorology-Hydrology-Hydraulics-Geotechnics.

2. Preparation of operationally applicable tools for emergency management in large as well as small scale context.

Published by Copernicus Publications on behalf of the European Geosciences Union. 


\section{Simulation of extreme precipitation events and evaluation of their variability}

A main cause for extreme flood events is long-lasting and/or intensive precipitation. The detailed knowledge of its distribution, intensity and spatiotemporal variability is a fundamental prerequisite for hydrological flood modelling and subsequent operational flood risk management. For hydrological modelling, temporal and spatial high resolution precipitation data can be provided through meteorological models, where all meteorological scales from synoptical to regional and local scales (catchments of small rivers) are considered simultaneously. A crucial meteorological question is the estimation of the variability of realistic, physically-based extreme precipitation events.

\subsection{Model domain and model setup}

In order to simulate appropriate discharges in hydrological modelling, precipitation for the whole catchment area of the Upper and Middle Elbe River, which was severely damaged during the 2002 flooding event, is required. The catchment area includes parts of the Czech Republic, where the catchment area is surrounded by the Giant Mountains, Eagle Mountains, the Bohemian-Moravian Heights (which is the main water divide between Elbe and Danube), the low mountain range Bohemian Forest, the Upper Palatinate Forest and the Ore Mountains, and parts of eastern Germany. Simulations based on the COSMO model, which is the operational weather forecasting model of the German Weather Service (DWD), were carried out. More details to this model can be found in Steppeler et al. $(2002,2003)$ and Doms and Schättler (1999). A detailed description of the COSMO model and its dynamical and physical core can be found in Rockel et al. (2008). The model domains were set up with different grid resolutions ( 28 and $7 \mathrm{~km}$ ), where the finer resolution domain was nested into the coarser grid (Fig. 1).

The coarse grid covers Central Europe and has $70 \times 60$ grid points with 35 levels and a horizontal resolution of $0.25^{\circ}$, which is about $28-\mathrm{km}$ grid spacing. GME analysis data serve as boundary and initial data for the coarse model domain. The results of these model runs are used as boundary data for the nested model simulations and are passed every $6 \mathrm{~h}$. The latter are performed with $90 \times 75$ grid points, 35 levels and a horizontal resolution of $0.0625^{\circ}$, which is approx. $7 \mathrm{~km}$. Both models runs with a time step of $40 \mathrm{~s}$.

\subsection{Validation}

Sensitivity studies were conducted to obtain a suitable model configuration (initial and boundary data, time step and orographic filtering). The results show that the operational configuration of the COSMO model at DWD fits best with respect to the measurements. The simulations (both $28 \mathrm{~km}$ and $7 \mathrm{~km}$ ) were started at 6 August 2002 and were terminated at

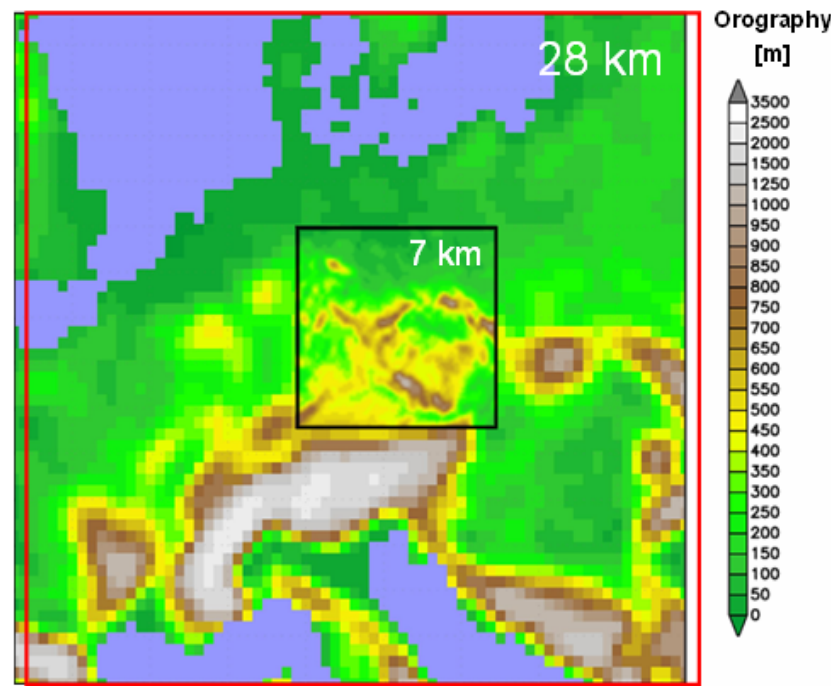

Fig. 1. The model domains. The coarse grid covers central Europe, and the catchment area is nested into the coarse grid with a higher resolution. The red box denotes a shifting of the synoptic weather conditions of two grid boxes (about $56 \mathrm{~km}$ ) to the East.

14 August 2002. The first $6 \mathrm{~h}$ were not taken into account for evaluation, allowing the model to spin-up. The model results were available for full 8 days, covering the precipitation event. The model simulation with $7-\mathrm{km}$ grid spacing, which is used as reference run, fits the measurements quite well, despite an underestimation of the maximum at 12 August. In such extreme events a high data uncertainty has to be taken into account, but the results score reasonably well.

\subsection{Variation of large-scale forcing}

On the basis of the observed Elbe flood event in August 2002, the weather conditions were shifted to North, East, South and West with respect to the orography by 28 and $56 \mathrm{~km}$, respectively. This amount corresponds to one and two grid boxes of the coarse model domain and corresponding scenarios are hence denoted by the symbols N1, N2, E1,.., W2 below. The shifting distances can be related to the forecast uncertainty of the large-scale models due to the model grid resolution, which is between 40 and $100 \mathrm{~km}$. The surface and the soil fields were not shifted to avoid inconsistencies with respect to the orography. There is no need to adapt them because they are less affected by the shifting of atmospheric fields. At a resolution of $28 \mathrm{~km}$, unbalanced atmospheric fields at the boundaries were quickly balanced by the model, so that the results could be used as shifted and balanced input for the nested run. Two additional ideas were followed to increase the precipitable water in the atmosphere. First, the relative humidity was increased by $5,10,15$, and $20 \%$, respectively, while the upper limit remains $100 \%$. Second, the temperature was increased in four steps $(0.5,1,1.5$, and $2 \mathrm{~K}$ ) while the relative humidity remained constant. Below, 
daily precipitation sum for the August 2002 Elbe flooding

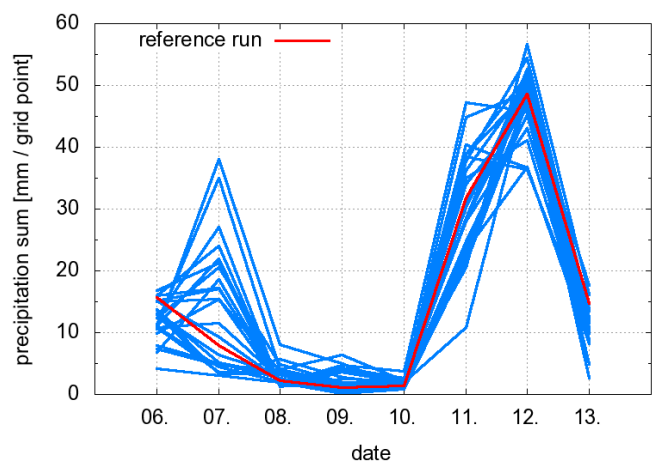

sum of averaged precipitation differences

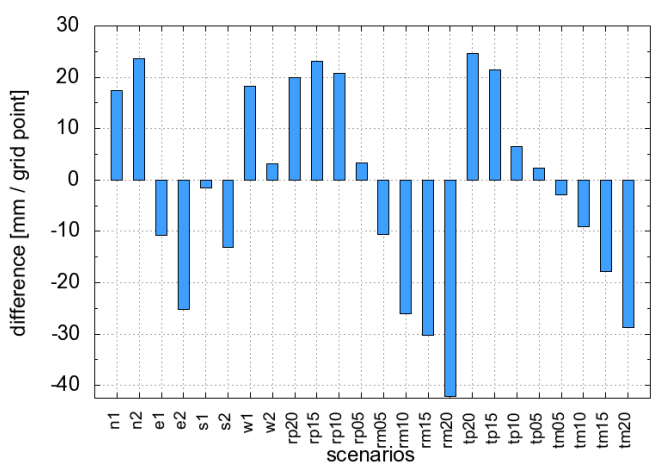

Fig. 2. Time series of the domain-averaged daily precipitation sum of the reference run $(7 \mathrm{~km})$ and the scenarios for the August 2002 Elbe flooding event (left) and the sum of the differences with respect to the reference run (right).

these scenarios are denoted by RP05,..., RP20 (increased relative humidity) and TP05,.., TP20 (increased temperature). Both methods result in a change of specific humidity. The same was done by decreasing the temperature and the specific water content in the same steps. A detailed description of the method and the results can be found in Schlüter and Schädler (2010).

While the shifted simulations show a high variability on 7 and 11 August 2002, the maximum on 12 August does not vary much but nearly all shifted scenarios produce higher maxima that day. The sums of the averaged precipitation differences show the dependency to the shifting (Fig. 2). While the shifting to North (N1 and N2) results in distinct excess of the precipitation, the precipitation with a shifting to East (E1 and E2) is less compared with the reference run. In three of four cases, the shifting of 56-km results in a higher and lower precipitation. The spatial distribution of the precipitation pattern is not shifted in the same direction as the shifting of the general weather situation. They have a considerably different structure because the shifting of convective weather conditions implies a change in the synoptic structure.

The scenarios with modified specific humidity show distinct changes in the precipitation pattern. As we expect, the amount of precipitation decreases when specific humidity decreases and increases rapidly when specific humidity increases, but the spatial distribution differs clearly to some extent, whereas the precipitation maxima over the Ore Mountains and the southern catchment area remained unchanged. The sensitivity is basically limited to 7 and 11 August, similar to the sensitivity of the shifted scenarios. The overall sum of the precipitation reaches a maximum during the increase of relative humidity, which cannot be exceeded, because of the limitation of the relative humidity to $100 \%$. It can be seen that some of the synthetic events produce higher precipitation than the reference run, so we can conclude that the precipitation pattern could have considerably been more intensive if the weather conditions had been slightly different during that period. Half of the scenarios led to more preci- pitation, so, from the meteorological point of view, the event in August 2002 can be regarded as an average event. The results show that the sensitivity of modelled precipitation is highly dependent on the initiating weather conditions. While $\mathrm{Vb}$ weather conditions are quite sensitive to modifications, homogeneous precipitation events are more insensible. The simulations are used within hydrological models for coupled scenario computations for extreme events in order to evaluate the hazard potential for a $60-\mathrm{km}$ stretch of the Elbe River between Wittenberg and Aken in order to assess the sensitivity of the discharge with respect to the scenarios.

\section{Large-scale hydrologic simulation for operational flood management in the Elbe basin}

Evaluation of flood risk and operational flood management in the Elbe basin require comprehensive knowledge of its flow process under extreme conditions. However, difficulties arise due to the fact that extreme (and rare) flood events may have different characteristics which are partly not included in available historical records. Like already shown in Sect. 2.3. for the weather situation releasing the August 2002 flood, it is hence important to extend available samples of extreme flood events (here flow hydrographs) by simulated events with multiple characteristics (extreme flood scenarios). For this purpose, operational hydrologic modelling systems were advanced to show their applicability for extreme flood events in the Elbe basin (Middle Elbe river till Dessau, catchment area $70000 \mathrm{~km}^{2}$, see Fig. 3).

In the Czech basin part, the flood forecast system AQUALOG was used. In this system, observed precipitation depths and temperatures were interpolated into a $1-\mathrm{km}$ grid using the inverse-distance method. Snow-melt and runoff generation were simulated in a 6-h time step with conceptual modules of the energy based model SNOW-17 and of Sacramento/SACSMA (NWS, 1999, 2007) in the scale of sub-basins of size from 5 to $30 \mathrm{~km}^{2}$. For runoff concentration in meso-scale catchments, unit hydrograph was applied. Compared to a 


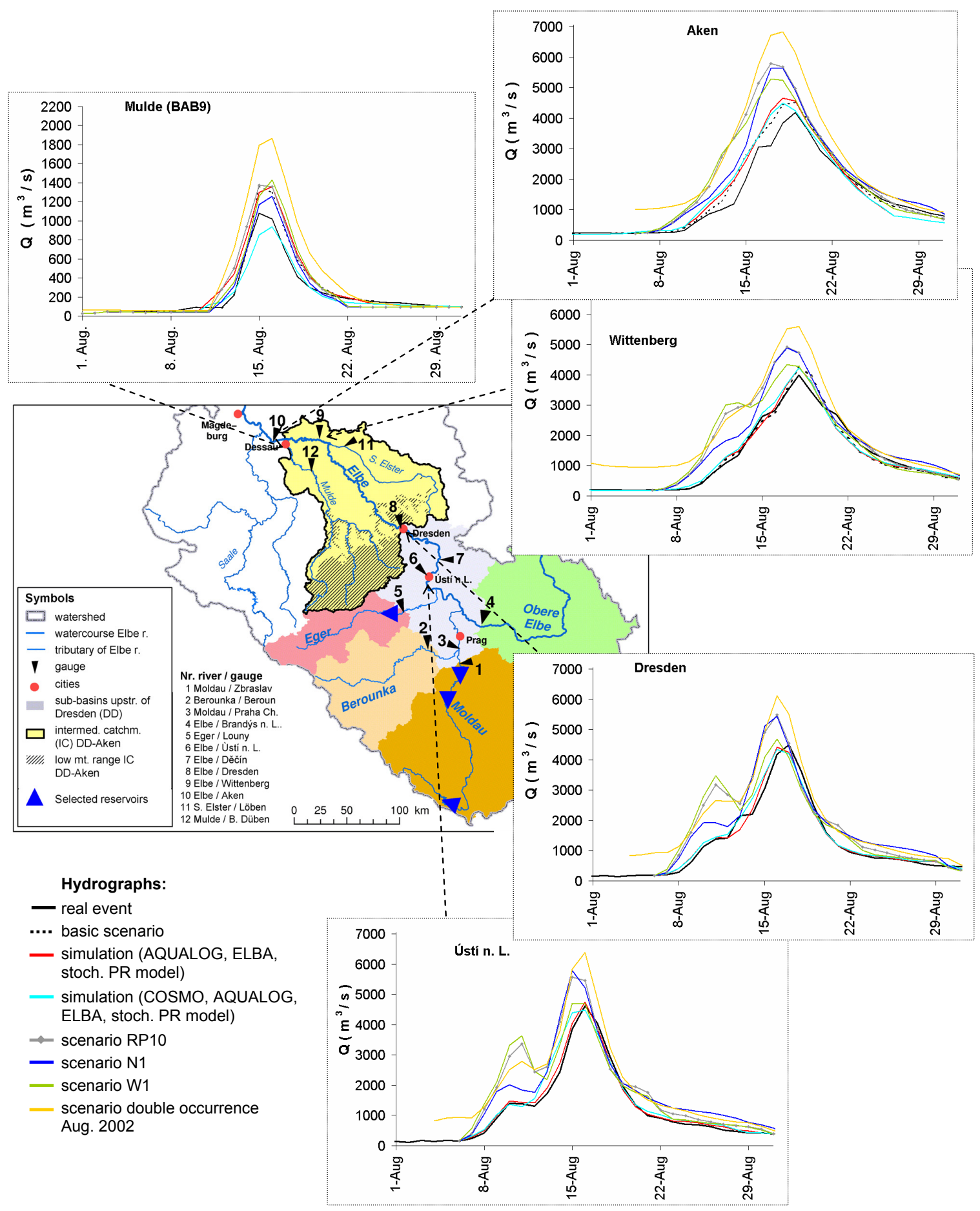

Fig. 3. Observed and simulated flood event of August 2002 in the Elbe basin upstream of Dessau. Compared to the real event, various scenarios show a considerable spectrum of possible event characteristics and thus the need of flexible strategies in operational flood management.

former model version, recalibration was performed using 2000-2006 rain gauge data. Where only daily precipitation measurement was available, radar reflectivity time series were used to proportionate distribution in 6-h time step. Subsequently, available flood-routing modules (translation- diffusion analogy, Muskingum-Cunge) were used to simulate the development of hydrographs in the river network till the Czech-German borderline. It is emphasized that operation of large reservoirs, especially at the Vltava river, was embedded into the flood-routing procedure. This reservoir 
operation was based on currently valid, official operation rules with various goal criteria (e.g., "maximum safe V1tava river flow in Prague" of $1500 \mathrm{~m}^{3} / \mathrm{s}$ ) and on comprehensive expert knowledge about reservoir impact gained in former studies (Hladný et al., 2004; Kašpárek et al., 2006). In the simulation of flood events (or flood scenarios), mentioned goal criteria were evaluated vs. event-specific hydrologic conditions to derive an optimal reservoir operation.

In the German reach of the Elbe river, a translationdiffusion model analogous to the flood forecast system ELBA was applied to rout simulated flood waves from the borderline to the investigation area of the Middle Elbe river. To superpose flood waves of the intermediate German basin part, a large-scale and task-specific stochastic precipitationrunoff (PR) model was developed. Distributed input to this modelling system was derived by interpolation of observed precipitation depths (inverse-distance method) and temperatures (modified nearest-neighbour method) as well as by a snow-compaction model. Flow hydrographs of the intermediate basin part (for diagnosis of the PR model) were estimated from observed flow series of Elbe and tributary gauges using a combined method of flow routing and regression analysis. With the derived daily input and flow series 19631996, the structure of the stochastic PR model was developed and calibrated in a stepwise procedure of complementary model modification and diagnosis. This procedure led to a differentiated model structure mainly consisting of cascades of conceptual reservoirs, seasonal patterns, indices of hydrologic catchment state and spatial input distribution and (preferably weak) non-linear tuning functions. Altogether, the essential catchment- and scale-specific hydrologic processes are reliably represented in this model.

Reliability of mentioned models (without recalibration) was analysed for extreme flood events (mainly those of August 2002 and March-April 2006 currently discussed as major reference events of flood protection). Due to strong event-specific retention effects, especially during the $\mathrm{Au}-$ gust 2002 flood along the (German) Elbe and Mulde rivers (dike breaches, backwater effects), the analysis was related to a basic scenario with homogenised conditions in the German intermediate catchment (assumption of no event-specific retention effects). After successful validation of the PR models (also for the major Czech tributaries and for the overall catchment at gauge Aken), this basic scenario was defined as reference for the evaluation of further simulations which were all performed under corresponding conditions.

After coupling of the hydrologic models with COSMO, simulations with this hydrologic-meteorological modelling system partly revealed deficits at the scale of the major tributary catchments shown in Fig. 3. These deficits rather concern the temporal development of hydrographs than their magnitude and may thus be explained by deficits in the spatio-temporal resolution of the simulated precipitation depths at that scale. However, in aggregated tributaries, these deficits compensate more and more until simulated and ob- served hydrographs fit very well at the scale of the overall basin of the Middle Elbe river (gauge Aken, see Fig. 3). Based on the capability of coupled simulation of large-scale flood events, a set of 25 extreme flood scenarios was defined and analysed in three principal ways.

1. Gradual modification of process variables: beside other hydrologic variables, input depths of the major releasing event and of the 30-day period preceding the major event of the August 2002 flood were increased by each $20 \%$. As expected, these modifications lead to significantly increased floods. In comparison to the basic scenario, peaks of the scenario with modified major event increased from 1360 to $1720 \mathrm{~m}^{3} / \mathrm{s}$ at the Mulde river (site of the bridge of Bundesautobahn 9 "BAB9", $12 \mathrm{~km}$ from the mouth and upper boundary of the hydraulic modelling area, see Sect. 4), from 4620 to $6450 \mathrm{~m}^{3} / \mathrm{s}$ at the Elbe gauge Ústí n. L., from 4200 to $5440 \mathrm{~m}^{3} / \mathrm{s}$ at the Elbe gauge Wittenberg and from 4480 to $6340 \mathrm{~m}^{3} / \mathrm{s}$ at the Elbe gauge Aken. For the scenario with modified preceding period, peaks increase to $1650 \mathrm{~m}^{3} / \mathrm{s}$ (BAB9), $6820 \mathrm{~m}^{3} / \mathrm{s}$ (Ústí n. L.), $5870 \mathrm{~m}^{3} / \mathrm{s}$ (Wittenberg) and $6950 \mathrm{~m}^{3} / \mathrm{s}$ (Aken).

For meteorological scenario definition with modified air mass properties, see Sect. 2.3. Among these scenarios, TP15 and RP10 lead to increased flood levels in the Czech basin part and hence at the Middle Elbe river. For instance in RP10, already the first flood event of August 2002 in the Czech basin part (precipitation of 6-8 August) is increased (see Fig. 3). Its superposition with the Mulde peak, which is similar to those of the basic scenario, enhances the rise of the overall event. Furthermore, flood duration is increased, e.g., from 6 days (basic scenario) to 8 days on a level $>3000 \mathrm{~m}^{3} / \mathrm{s}$ which was critical regarding dike safety during the real event. Due to hydrologic memory, also the major peak in the Czech basin part is increased to $5560 \mathrm{~m}^{3} / \mathrm{s}$ at Ústí $n$. L. (compared to $4620 \mathrm{~m}^{3} / \mathrm{s}$ of the real event). At a later stage of the event, peaks of Wittenberg and Aken are increased to $4930 \mathrm{~m}^{3} / \mathrm{s}$ and $5790 \mathrm{~m}^{3} / \mathrm{s}$.

2. Spatial shift of weather fields: (see Sect. 2.3.) among these scenarios, increased flood levels at the Middle Elbe river were identified for N1, W1 (see Fig. 3) and N2. In N1 and N2, flood peaks of the Mulde river (BAB9) decrease slightly (peak values about $1250 \mathrm{~m}^{3} / \mathrm{s}$ ), but the events in the Czech basin part (gauge Ústí n. L.) increase. Hence, also the peaks of Wittenberg increase to about $4950 \mathrm{~m}^{3} / \mathrm{s}$ and those of Aken to $5630 \mathrm{~m}^{3} / \mathrm{s}(\mathrm{N} 1)$ and $5730 \mathrm{~m}^{3} / \mathrm{s}$ (N2). Other event characteristics were identified for W1. Whereas the major event in the Czech basin part and thus the peak at Wittenberg $\left(4340 \mathrm{~m}^{3} / \mathrm{s}\right)$ are slightly lower than those of the basic scenario, the first flood event in the Czech basin part (precipitation 6-8 August) and the event of 
the Mulde river (peak $1430 \mathrm{~m}^{3} / \mathrm{s}$ at BAB9) are significantly increased. At the gauge of Aken, this results in an increased flood duration (similar to those of RP10) and also to an increased major peak of $5300 \mathrm{~m}^{3} / \mathrm{s}$.

3. Recombination of observed event elements: these event elements include units of atmospheric circulation patterns ACP (Gerstengarbe and Werner, 2005) and their precipitation and temperature patterns (provided that similar ACP transitions occurred in the observed historical series), catchment states (moisture conditions, snow cover), flood-protection measures (reservoirs, polders) and special events like dike breaches. An example is the recombined scenario based on the August 2002 flood for which the occurrence of the extreme precipitation of 2-13 August 2002 (with ACP "Trough Central Europe - TCE" 9-13 August) was assumed to occur once more prior to 21 July 2002 when a TCE event with high precipitation amounts also occurred in reality. With increased moisture resulting from this scenario pre-event, the first flood event of August 2002 (due to precipitation of 6-8 August) in the Czech basin part (peak of $2780 \mathrm{~m}^{3} / \mathrm{s}$ in Ústí $\mathrm{n}$. L.) and the Mulde flood (peak of $1870 \mathrm{~m}^{3} / \mathrm{s}$ ) are both increased (see Fig. 3). Due to their superposition, extreme flow values occur earlier than in the basic scenario, e.g., the level of $3000 \mathrm{~m}^{3} / \mathrm{s}$ is exceeded two days earlier in Wittenberg and Aken. This flood level is still significantly exceeded by the peaks of the major event with $6130 \mathrm{~m}^{3} / \mathrm{s}$ in Ústí n. L., $5600 \mathrm{~m}^{3} / \mathrm{s}$ in Wittenberg and $6830 \mathrm{~m}^{3} / \mathrm{s}$ in Aken.

In order to investigate whether a similar (or higher) flood magnitude may also occur at the usually dominating flood type due to snow-melt in combination with rainfall, the following scenario (among other scenarios) was analysed. The extreme snow cover of 2006, e.g., state of 27 March 2006 was combined with the extreme precipitation and relatively warm temperatures of 68 May 1978 before the meteorological course of spring 2006 is continued from 5 April 2006. This recombination corresponds to a realistic sequence of atmospheric circulation patterns (West cyclonic - Cyclone Central Europe - Anticyclone Central Europe). In this scenario, an extreme initial condition (snow depth) occurs in all basin parts and the course of thaw is very unfavourable due to high temperature and rainfall. The most extreme flood reactions were simulated in the areas of the Ore and Giant Mts. In the area of the Middle Elbe river, the Mulde peak (BAB9) reaches $2100 \mathrm{~m}^{3} / \mathrm{s}$ and Wittenberg peaks at $5300 \mathrm{~m}^{3} / \mathrm{s}$ (following a peak of $4980 \mathrm{~m}^{3} / \mathrm{s}$ at Ústí n. L.). After superposition (with assumptions of the basic scenario), the peak of Elbe gauge Aken reaches $6760 \mathrm{~m}^{3} / \mathrm{s}$ - the same order of magnitude like in above described, recombined scenario with double occurrence of August 2002 rainfall.

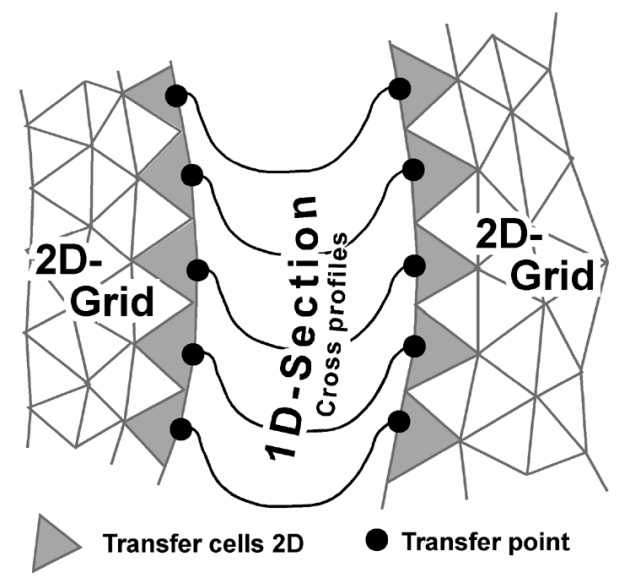

Fig. 4. Model interlinking.

Altogether, results of the simulations reveal that defined scenarios have multiple characteristics of extreme flood hydrographs in the investigation area of the Middle Elbe river. Partly, scenario hydrographs significantly exceed observed flood peaks and flood durations of above mentioned reference events (2002 and 2006). Furthermore, the rise of flood hydrographs is partly quicker in some scenarios (meaning less time to prepare flood-protection measures). The present study thus shows that flood management is a challenge beyond experiences gained during the mentioned extreme event of the last years. To derive flexible strategies of an enhanced operational flood management in the area of the Middle Elbe river, a set of relevant extreme flood scenarios was provided for further research activities (hydraulic-numerical modelling, evaluation of dike safety, risk analysis) which will be considered in the following chapters.

\section{Real-time hydraulic simulation}

To act adequately during real-time flood management in extreme situations, detailed knowledge of the hydraulic situation is essential, e.g. for early identification of possible failure locations or vulnerable supply roads. Anticipatory hazard analysis often cannot be employed because of the multiplicity of possible events. Therefore, numerical models are required to enable the user to quickly recognize current regional as well as local hazards and to evaluate possible options for action. Major demands for those models are fast computation as well as maximum user-friendliness in starting and analysing flow calculations. Within the hydraulic part of the described the project, a tool was developed to fulfill these demands by using an innovative 1-D/2D-interlinked hydraulic method and integrating this into a Geographic Information System (GIS). The hydraulic model combines the following methods within one research area (see also Fig. 4):

- 1-D models for areas with distinct dominant flow for all discharges (e.g. river or flood channels). 
- 2-D models of areas with definitive multidimensional flow (e.g. floodplains, conjunctions, protected areas behind dikes).

The model is based on the 2-D-module FLUMEN (fluvial.ch, Schwyz) with which the 2-D shallow water equations are solved using a finite volume method with explicit time discretisation based on an unstructured triangulated mesh. The program calculates detailed information on the distribution of depth-averaged flow velocities, water levels and bed shear stresses within the computational area. The model is linked to the 1-D-module FLUSH which is based on the 1-D Saint Venant equations. The parameterization of flow resistance is done using the Manning equation. A consistent geocoding of the 1-D and 2-D models is established using a polygon of the river course.

The flow over an imaginary weir is taken as interface between the two modules. The height of the weir is either defined by the height of the dike included in the 1D-crossection or by the topography of the 2-D-calculation mesh. The amount of water exchanged by the two modules is estimated using a Poleni-type formula with respect to backwater effects (Beffa, 2006). Within the Elbe-project this method was tested in detail and compared to commonly used models. With an overall reduction in computational time of $70-85 \%$ combined with an almost insignificant loss in accuracy compared to a regular 2-D-model the results offered by the interlinked model were quite promising for future calculation of flood events.

For real-time use the interlinked model was integrated into a GIS and especially adapted to the needs of emergency management. This was done in close cooperation with the project partners and possible later users. So even persons without deep hydraulic or computational knowledge can start their own hydraulic calculations and look at its results. Also an overlay with other topographic data (e.g. maps or aerial pictures) is easily possible. At its present state the system Flow GIS concludes the following possibilities:

- Starting of hydraulic calculations with:

- import, definition and editing of hydrographs,

- selection of an arbitrary calculation period,

- integration of possible dike failures/log jams.

- Visualization of simulation results:

- 2-D-visualization by GIS (e.g. water depth or flow vectors),

- diagrams (e.g. longitudinal sections or hydrographs),

- GUI-guided creation of individual cross sections and gauges.
- Dike/building overtopping analysis:

- dikes and important buildings situated within the research area are stored in the system; their inundation risk can be analysed via simple mouse click,

- interface to Geotechnics (detailed dike analysis, see Sect. 5),

- at endangered sections dike failures or log jams can be created GUI-guided and integrated into further calculations.

The underlaying GIS was choosen to be ARC GIS 9, as it is widely spread within the hydraulic users community and also offers a lot of options for future development. But also an integration into a different GIS is due to the module-based programming of the tools possible on need with reasonable effort. Figure 5 shows a principle scheme of the real-time use, based on actual boundary conditions, hydraulic simulation and real-time analysis of the calculated results.

The describes modular tool FlowGIS was developed and set up for a section of the Elbe River between the cities of Wittenberg and Aken with focus on the city of Dessau. Employing this tool one can identify, quantify and visually display the resulting endangering in case of an extreme flood event. Based on the resulting information offering high spatial resolution the responsible crisis management group can evaluate possible options for action and initiate concerted measures like dike reinforcement in endangered areas, flooding of polders or even evacuation.

The developed system enables the user to simulate its own, hydraulically realistic and transient flow scenarios based on actual hydrologic prognosis. In case of emergency management, the users are now offered a tool to classify, e.g. their dike gates in order of their inundation times or - in extreme cases - to detect flow path even within inhabitated areas important, e.g. for evacuation or for optimization of plans of action for rescue forces. Due to the fast calculation even the simulation and analysis of different protection measures (e.g. sandbag dams or emergency flooding of polders) is possible during the flood event.

\section{Dike-Information-System (IS-dikes)}

Since a considerable portion of existing dikes do not correspond to the requirements according to the current state of technology and standards, for embankments like these up to now there has been no tool, with which it has been possible to observe the condition of the dikes, to make a quantitative evaluation of their anticipated behaviour in the course of a flood and to be able to have the resulting information available in a suitable form for those responsible (emergency management, etc.) 


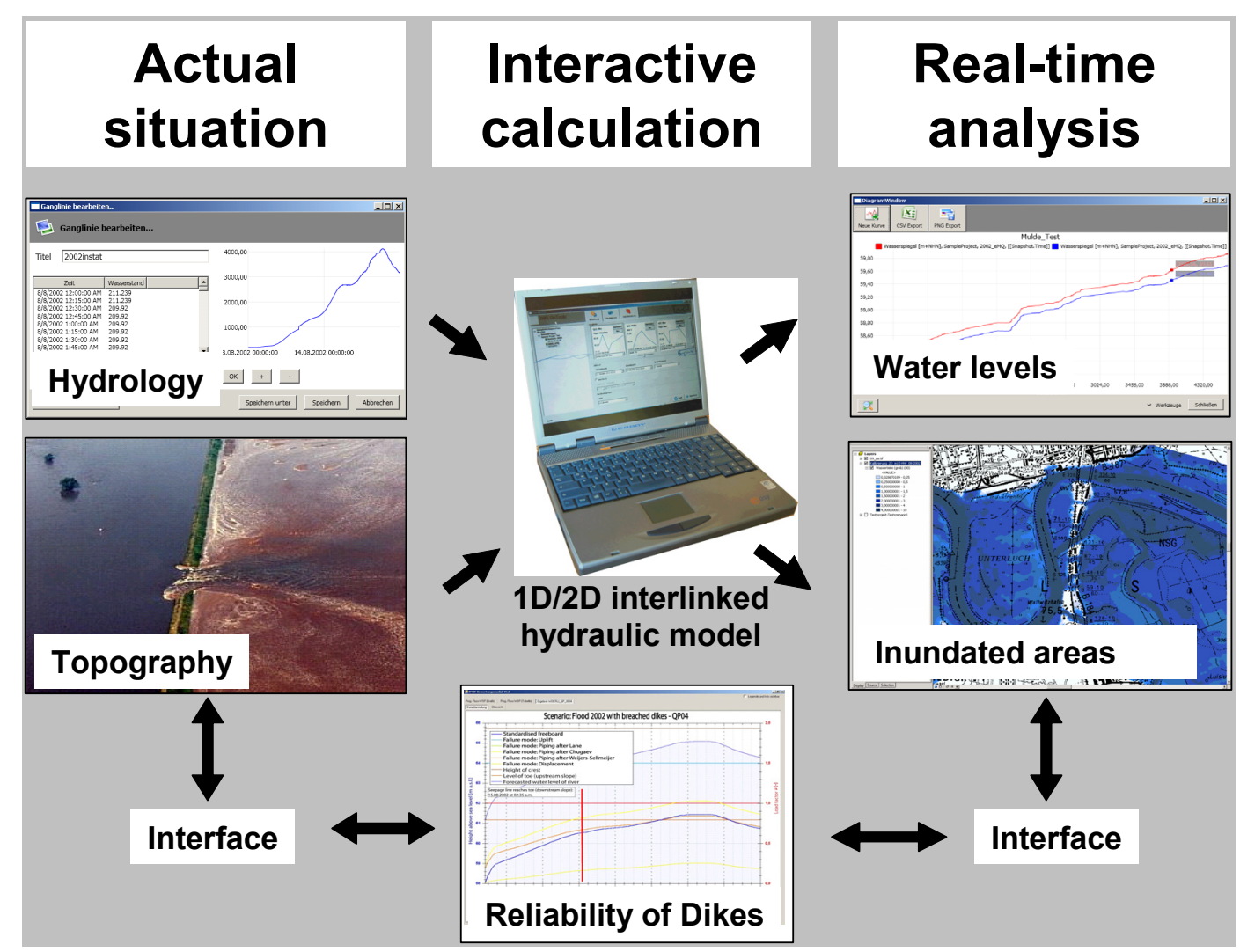

Fig. 5. Principle scheme for real-time use.

So it was the aim of a further subproject, which was carried out at the Institute of Soil and Rock Mechanics, Karlsruhe Institute of Technology (KIT), in close cooperation with Consulting Engineers Dr.-Ing. Karl Kast + Partner (GbR), Ettlingen, to continue the development of an universal information and online monitoring system for river dikes (DikeInformation-System - IS-dikes). In advance this IS-dikes was developed on behalf of the authority for flood control measures in the federal state North Rhine-Westphalia, where the system in this form has already been successfully applied by the responsible authorities for a number of years along the lower Rhine between Bonn and the Dutch border.

The GIS-system has documentation available on dike safety for certain sites as basic information. With regard to its application for dike defence measures a monitoring and evaluation module is being developed taking into consideration the anticipated water levels in the river, i.e. the information gained from various online-measurements in situ. The measuring technique to be used, i.e. the parameters to be recorded are oriented towards the individual and specific requirements, which result from an analysis of the weak points along the dike section to be monitored. In principle in the present context the application of all types of technical measuring components could be considered, which permit the determination of the major influencing factors, such as pressure, moisture distribution and seepage, directly or indirectly.
The Elbe River at Dessau was selected as a pilot area for testing the further developed information system (cf. Fig. 6); in agreement with the responsible authorities of the federal sate Saxony-Anhalt 6-dike sections for integration of corresponding data in the IS-dikes were chosen. Amongst others the criteria for the selection were old dikes with a mostly homogeneous structure, which would not be refurbished in the foreseeable future, as well as dike sections with known weaknesses.

To obtain an example for the evaluation of the stability of a dike section, piezometers were installed in several cross sections of one dike section (Fig. 7). These online-sensors make it possible to determine the phreatic line in the dike structure as well as the pressure conditions below the cohesive top layer. Information on the structure of the dike as well as of the subsoil is also available as a result of borings. The measurements recorded online during the course of a flood event are taken into consideration in the evaluation of the stability of the dike with regard to the following mechanisms of failure: overtopping, embankment instability, uplift of the clayey top layer at the downstream toe, piping by heave and displacement. Of course the proof of stability necessary for the evaluation is performed according to the relevant regulations. As an example the illustration of the result of an evaluation of one dike cross section for all failure modes is shown in Fig. 8. It becomes apparent, that the behaviour of 


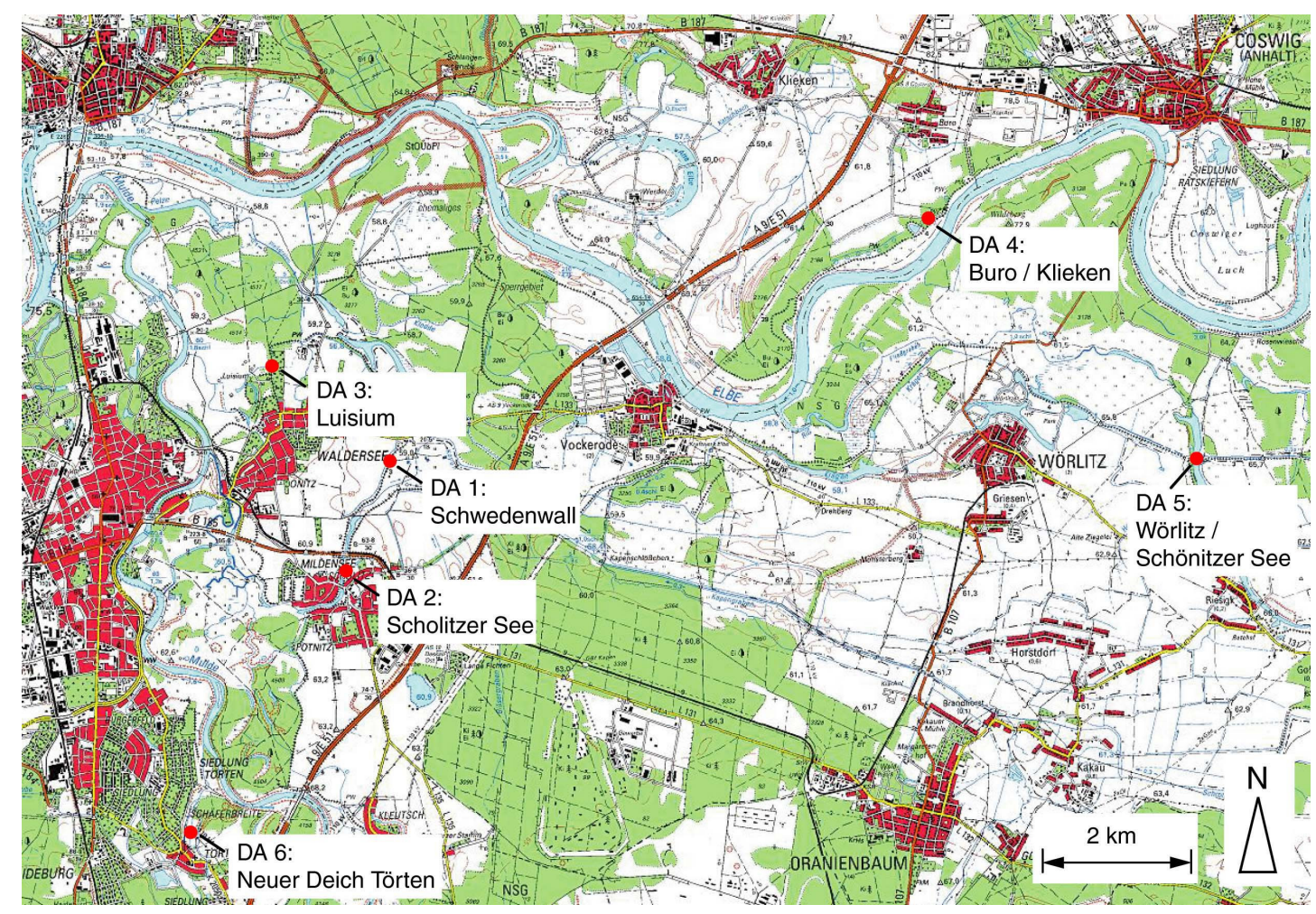

Fig. 6. River Elbe at Dessau and monitored dike sections (DA) 1 to 6.

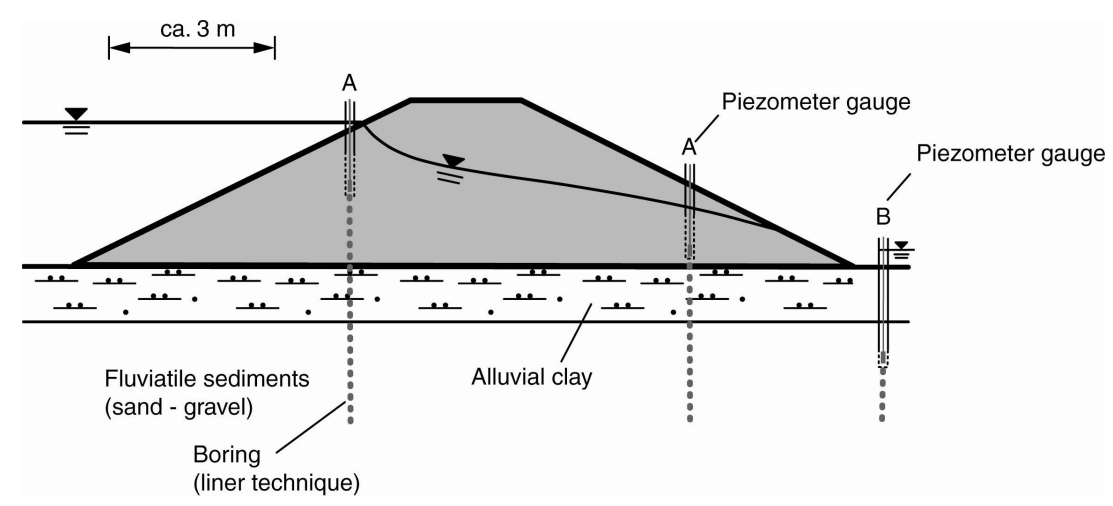

Fig. 7. Cross section of a dike at the River Elbe with piezometers for online data transfer.

the dike in question can be predicted on the basis of available geotechnical data, online data and the forecasted water level in the river coming from the real-time hydraulic simulation. On the basis of trigger values, e.g. defence measures, can be initiated to stabilize the dike in question at short notice (emergency management). The application of the IS-dikes is possible for any dikes. It has to be emphasised, the the use of the IS-dikes needs an certain amount of geotechnical data of dike and subsoil.

\section{Conclusions/outlook}

During the project it could be shown, that a coupled treatment of the flood-process-chain meteorology-hydrologyhydraulics-geotechnics and thus an integrated quantification of all relevant impact is possible. The modelled scales ranged from large-scale analysis of precipitation (nested simulation of general weather situation) and rainfall-runoff modelling integrated in space and time (hydrologic modelling of the whole German and Czech catchment area of the Elbe River) 


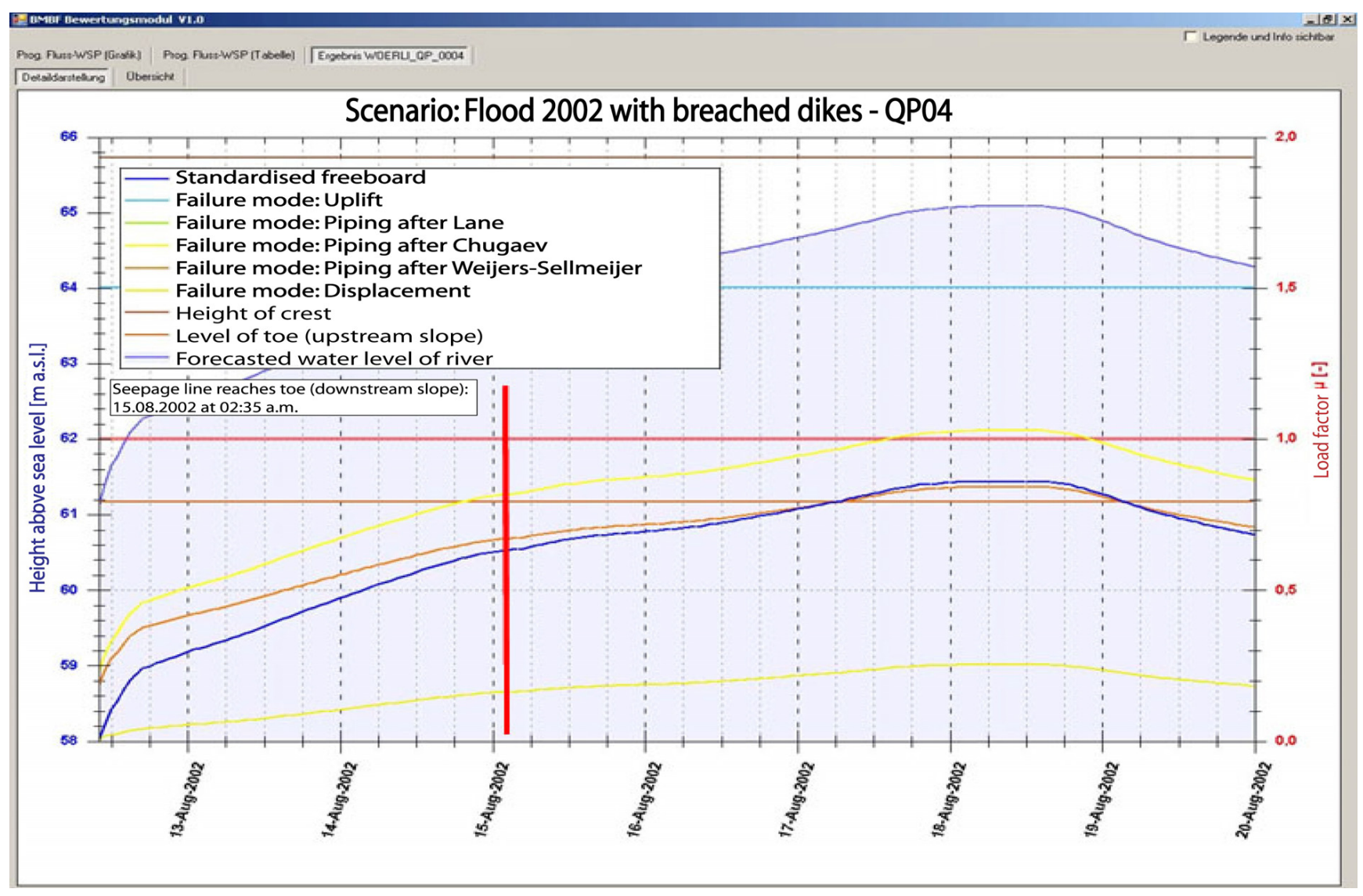

Fig. 8. Evaluation module - illustration of the result of an evaluation of a dike cross section for different failure modes (basis: szenario QP4).

as a basis for hydraulic simulation of possible flood scenarios to local quantification of protective measures (operational flood simulation and dike safety evaluation).

For a section of the Elbe River between the cities of Wittenberg and Aken an operationally applicable modular tool for use for example in emergency management with focus on the city of Dessau was developed and is ready for use. Employing this tool one can identify, quantify and visually display the resulting endangering in case of an extreme flood event. Based on the resulting information offering high spatial resolution the responsible crisis management group can evaluate possible options for action and initiate concerted measures like dike reinforcement in endangered areas, flooding of polders or even evacuation. Being the interface between water resources and disaster management the developed tools and scenario calculations are an essential, previously not available basis for the integrated quantification and evaluation of flood risks and the planning of retention measures in the whole Elbe catchment. Thereby they can contribute to a coordinated cross-border risk management at the Elbe River. By coupling of existing hydrologic models from Czech and German institutions there is now the possibility to quantify the effectiveness of retention areas located at the Upper Elbe during extreme flood situations with special focus on the Middle Elbe area. Even events exceeding the historical one can now be handled. Accounting for those effects even the still existing dubiety in the hydraulic flood profile of the Elbe could be eliminated.

This was realised by integration and further development of existing tools for simulation of single processes starting with the general weather situation and up to the local inundation risk. Important subgoals were the use of existing tools, their extension using innovative techniques and the possibility of a coupled use for the simulation of extreme events. Due to the applied modular conception a flexible use of every developed tool within the Elbe basin as well as any other river catchment area is possible. Consequent continuation of priliminary work and close cooperation with responsible authorities were the basis of the successful realisation of the project goals.

Acknowledgements. The project was is funded by the German Federal Ministry of Education and Research (BMBF) in the frame of the RIMAX program. The support is gratefully appreciated.

Edited by: M. Disse

Reviewed by: U. Müller and another anonymous referee 


\section{References}

Beffa, C.: Integration von ein- und zweidimensionalen Abflussmodellen, TU Dresden, Dresdener Wasserbauliche Mitteilungen, Heft 32, 533-540, 2006.

Doms, G., Schättler, U., and Deutscher Wetterdienst: The nonhydrostatic limitedarea model LM (Lokal-Modell) of DWD. Part I: Scientific documentation, Geschäftsbereich Forschung und Entwicklung, available at: http://www.cosmo-model.org (last access: 11 May 2010), 1999.

Gerstengarbe, F.-W. and Werner, P. C.: Katalog der Großwetterlagen Europas (1881-2004) nach P. Hess und H. Brezowski, 6. verbesserte und ergänzte Auflage (Catalogue of Atmospheric Circulation Patterns of Europe (1881-2004) according to P. Hess and H. Brezowsky, 6th corrected and advanced ed.), Potsdam, PIK-Report No. 100, 2005.

Hladný, J., Krátká, M., and Kašpárek, L. (Eds.): August 2002 catastrophic flood in the Czech Republic, Ministry of Environment of the Czech Republic, Prague, 2004.

Kašpárek, L., Novický, O., Jeníček, M., and Buchtela, S. (Eds.): Influence of large reservoirs in the Elbe River basin on reduction of flood flows, T. G. Masaryk Water Research Institute, Prague, 2006.
NWS: National Weather Service River Forecast System (NWSRFS) User's Manual, available from NOAA/National Weather Service, Office of Hydrology, 1325 East-West Hwy, Silver Spring, MD 20910, USA, 1999.

NWS: National Weather Service River Forecast System (NWSRFS) User's Manual, available at: http://www.nws.noaa.gov/oh/hrl/ nwsrfs/users_manual/htm/xrfsdocpdf.php (last access: 11 May 2010), 2007.

Rockel, B., Will, A., and Hense, A.: The regional climate model COSMO-CLM, Meteorol. Z., 17, 347-348 2008.

Schlüter, I. and Schädler, G.: Sensitivity of heavy precipitation forecasts to small modifications of large scale weather patterns for the Elbe River, in press, J. Hydrometeorol., 2010.

Steppeler, J., Doms, G., and Adrian, G.: Das Lokalmodell LM, Promet 27(3/4), 123-128, 2002.

Steppeler, J., Doms, G., Schättler, U., Bitzer, H. W., Gassmann, A., Damrath, U., and Gregoric, G.: Meso-Gamma Scale Forecasts Using the Non-hydrostatic Model LM, Meteorol. Atmos. Phys., 82, 75-90 2003. 